\title{
Heart rate and skin resistance during sleep before and after 60 hours of sleep deprivation
}

JAMES G. CRAIG, MICHAEL W. MCCABE, and WALTER D. FENZ, University of Waterloo, Waterloo, Ontario, Canada

Twelve male student volunteers were deprived of sleep for $60 \mathrm{~h}$. During the night before and during the night after deprivation, simultaneous recordings of heart rate and skin conductance were taken. When the night before deprivation was compared to the night after deprivation, heart rate was found to be significantly $(p<.05)$ higher, while skin conductance tended to be lower, interacting significantly $(p<.05)$ with time.

The literature includes at least two studies which report the autonomic activity following sleep onset after a prolonged period of sleep deprivation. Ax \& Luby (1961), studying five Ss, found a drop in skin conductance, in respiration rate and in muscle tension during the first $15 \mathrm{~min}$ following sleep onset, after $123 \mathrm{~h}$ of sleep deprivation. These findings are comparable to those of nonsleep-deprived Ss (Hawkins, Puryear, Wallace, Deal, \& Thomas, 1962; Tart, 1967) although they are somewhat more pronounced in the sleep deprived Ss. Johnson, Slye, \& Dement (1965) report on the autonomic activity of a 17 -year-old boy during $264 \mathrm{~h}$ of sleep deprivation and during several recovery nights. The most dramatic autonomic change after sleep onset was the rapid rise in skin temperature, and marked vasodilation. Heart rate decreased from 79 to 71 beats during the first $8 \mathrm{~min}$ of sleep, while skin resistance remained more or less constant throughout the night. Specific GSRs were completely absent and nonspecific GSRs greatly reduced throughout the first recovery night. Except for basal conductance, the study complements the findings by $\mathrm{Ax} \&$ Luby (1961).

The present study reports heart rate and skin resistance taken from 12 Ss throughout a control night and the first recovery night following $60 \mathrm{~h}$ of sleep deprivation. It is part of a larger study which was primarily concerned with investigating the relationships between autonomic indices of arousal and performance covering a wide spectrum of performance measures.

\section{METHOD}

Twelve male Ss between the ages of 18 and 27 (mean age $=21$ ) were tested in the research laboratories at Lakeshore Psychiatric Hospital. They were remunerated $\$ 100.00$ for taking part in the experiment. Each $S$ arrived in the laboratory on a Monday evening and stayed until Friday. The present report deals with physiological recordings obtained throughout sleep on the first night (Monday night) at the hospital, and a later night (Thursday night) following $60 \mathrm{~h}$ of sleep deprivation.

Recordings of heart rate and skin resistance were obtained from a Beckman Type R dynograph with GSR (Type 9892 A) and heart rate (Type 9857) couplers. Beckman bipolar electrodes and Beckman paste were used. Skin resistance electrodes were placed on the palm and back of the S's nondominant hand. Heart rate electrodes were placed on the ventral surface of the S's left and right forearms, using the same type of Beckman electrodes and electrode paste.

Five-minute samples were selected from stabilized, artifactfree activity 10 times during the before and the after deprivation nights: the first reading was taken just after "lights out," the following ones at $1 / 2-h$ intervals for $2 \mathrm{~h}$, and finally at 1 -h intervals for $5 \mathrm{~h}$. The night before deprivation, readings were taken from $11 \mathrm{PM}$ to about $6 \mathrm{AM}$. The night after deprivation, readings were taken from about 7 PM to about $7 \mathrm{AM}$, although the study only reports the 10 first readings during the recovery night, at comparable intervals to those during the predeprivation night.

RESULTS

Figure 1 presents mean heart rate for the first $7 \mathrm{~h}$ of sleep, during the nights before and after sleep deprivation. It may be seen that during both nights, heart rate decreased steeply during the first $2 \mathrm{~h}$, then more gradually for the remaining $5 \mathrm{~h}$. One difference between the two nights was that the steep heart rate deceleration occurred during the first hour of sleep during the night before deprivation, while it occurred only during the second hour of sleep during the night after deprivation. It may also be observed that heart rate during the night after deprivation was consistently higher than during the night before deprivation.

Analyses of variance performed on the heart rate data showed that heart rate was significantly higher $[F(9,90)=6.36, p<.05]$ the night after deprivation than the night before deprivation. Furthermore, both nights manifested a significant linear trend $[F(1,10)=5.70, p<.05]$, attesting to the reliability of the decline in heart rate during the night for both groups.

Findings for palmar conductance are presented in Fig. 2. In contrast to the patterns of heart rate which were similar for both nights, the same was not found to be true for palmar conductance. During the night before deprivation, palmar conductance rose from 9.3 micromhos just after the lights were turned out, to a peak of 19.3 micromhos $3 \mathrm{~h}$ later, then slowly declined. During the night after deprivation, on the other hand, palmar conductance remained relatively unchanged throughout the $7 \mathrm{~h}$, thus differing considerably from the pattern of palmar conductance the night before deprivation. At "lights out," after $60 \mathrm{~h}$ of sleep deprivation,

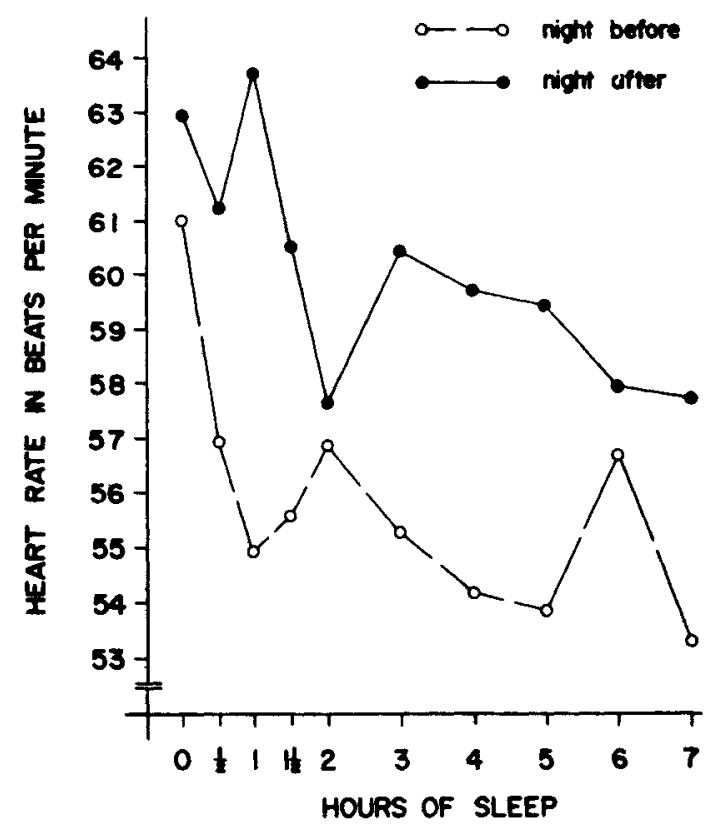

Fig. 1. Mean heart rate during the first $7 \mathrm{~h}$ of sleep, recorded the night before and the night after $60 \mathrm{~h}$ of sleep deprivation. 


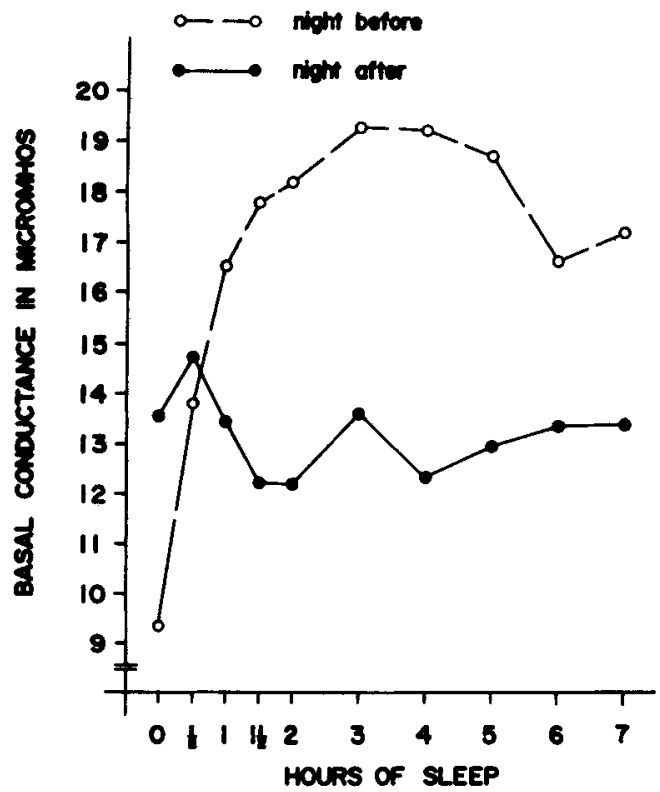

Fig. 2. Mean skin conductance during the first $7 \mathrm{~h}$ of sleep, recorded the night before and the night after $60 \mathrm{~h}$ of sleep deprivation.

basal conductance was 4.2 micromhos above the night before; after $7 \mathrm{~h}$, basal conductance was at about the same level, but now 4.8 micromhos below the night before.

An analysis of variance indicates that the interaction between the two nights and the 10 measurement periods was significant $[F(9,99)=2.52, p<.05]$.

\section{DISCUSSION}

During the first recovery night heart rate was higher, while palmar conductance was lower, than during the night before deprivation. The reason for this discrepancy is not clear. It is unlikely that the increase in heart rate can be attributed to an increase in body activity. Although body movement was not formally measured in the present experiment, Johnson et al (1965), and Williams \& Williams (1966), found significantly less body movement during the first night following sleep deprivation than during later nights. Casual observation of Ss during the recovery night in the present experiment confirms this observation.

A number of studies (Berger \& Oswald, 1962; Webb \& Agnew, 1965; Williams, Hammack, Daly, Dement, \& Lubin,
1964) report that total deprivation. of sleep results in an increase in the proportion of orthodox sleep (OS) to paradox sleep (PS) during the first recovery night. There is a study by Vimont-Vicary, Jouvet-Mounier, and Delorme (1966) which reports that, in cats, PS deprivation increased normal heart rate. If these findings can be applied to humans, a possible reason for the higher heart rate during the recovery night may be this PS-OS imbalance following sleep deprivation, due to the increase in OS during the recovery night.

Finally, the sharp increase in conductance during the night prior to sleep deprivation is not consistent with the literature. A possible explanation may lie in the hospital environment and the expectations about the experiment. The fact that this is not reflected in heart rate makes this interpretation nevertheless less plausible.

\section{REFERENCES}

AX, A., \& LUBY, E. D. Autonomic responses to sleep deprivation. Archives of General Psychiatry, 1961, 4, 55-59.

BERGER, R. J., \& OSWALD, I. Effects of sleep deprivation on behavior, subsequent sleep, and dreaming. Journal of Mental Science, 1962, 108, $457-465$.

HAWKINS, D. R., PURYEAR, H. B., WALLACE, C. D., DEAL, W. B., \& THOMAS, E. S. Basal skin resistence during sleep and "dreaming." Science, 1962, 136, 321-322.

JOHNSON, L. C., SLYE, E. S., \& DEMENT, W. Electroenceph alographic and autonomic activity during and after prolonged sleep deprivation. Psychosomatic Medicine, 1965, 27, 415-423.

TART, C. T. Patterns of basal skin resistence during sleep. Psychophysiology, 1967, 4, 35-39.

VIMONT-VICARY, P., JOUVET-MOUNIER, D., \& DELORME, F. EEG and behavioral effects of deprivation of paradoxical sleep in the cat. Electroencephalography \& Clinical Neurophysiology, 1966, 20, $439-449$.

WEBB, W. B., \& AGNEW, H. W., JR. Sleep: Effects of a restricted regime. Science, $1965,150,1745-1747$.

WILLIAMS, H. L., HAMMACK, J. T., DALY, R. L., DEMENT, W. C., \& LUBIN, A. Responses to auditory stimulation, sleep loss, and the EEG stages of sleep. Electroencephalography \& Clinical Neurophysiology, $1964,16,269-279$.

WILLIAMS, H. L., \& WILLIAMS, C. L. Nocturnal EEG profiles and performance. Psychophysiology, 1966, 3, 164-175. NOTE

1. This report is based on a thesis submitted by James G. Craig in partial fulfillment of the requirements for a M.A. degree. It was presented as part of a larger study, at the annual meeting of the Psy chonomic Society, St. Louis, Missouri, November 1968. The research was supported by Grant 2330 from the Medical Research Council, and Grant 74 of the Ontario Mental Health Foundation to Walter D. Fenz. The research was conducted at Lakeshore Psychiatric Hospital. 